\title{
Track Model: A Proposal of an Interactive Exhibit to Learn Aerodynamics
}

\author{
Sturm Heike (Corresponding author) \\ Centre of Math \& Science Education (Z-MNU), Institute of Biology Didactics, University of Bayreuth \\ Universitätsstrasse 30, D-95440 Bayreuth, Germany \\ Tel: 49-9492-600-596Ｆax: 49-921-552-696Ｅ-mail: heikesturm@yahoo.de
}

Sturm Gerd

Gymnasium Parsberg, Aschenbrennerstrasse 10, 92331 Parsberg, Germany

E-mail: g.sturm@yahoo.de

Bogner Franz X.

Centre of Math \& Science Education (Z-MNU), Institute of Biology Didactics, University of Bayreuth

Universitätsstrasse 30, D-95440 Bayreuth, Germany;

E-mail: Franz.Bogner@uni-bayreuth.de

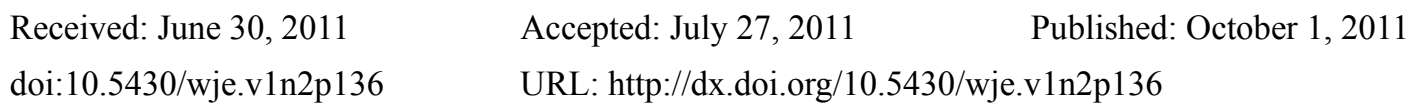

The study was supported by the University of Bayreuth.

\begin{abstract}
Bird flight and lift in general is a complex subject which is also difficult to teach in a classroom. In order to support the teaching of this curriculum-based subject, an interactive exhibit to demonstrate aerodynamic aspects of objects has been developed, implemented and evaluated with 262 middle school students. The empirical evaluation comprised a semantic differential in order to test the affectivity of the model as well as workbook analyses in order to measure potential cognitive gains. Factor analyses of the semantic differential responses revealed two factors with high factor loadings and high consistency. Qualitative analyses of the workbooks showed that $67 \%$ of the students added cognitive knowledge by experimenting with the track model. Conclusions are drawn concerning the added value of the implementation of our track model in school.
\end{abstract}

Keywords: Bird flight, Hands-on experiment, Biology education, Science education, Inquiry-based learning

\section{Introduction}

How do birds fly and why they do not drop down is a difficult to understand question in science education. Even university students of Physics often have difficulties to understand the physics of lift entirely (Anderson \& Eberhardt, 2001). Thus, it might be even harder for school students to understand the bird flight and the phenomenon of lift which in general is a challenge for any teaching approach. Only a few experiments are published which demonstrate some selected aspects of bird flight (eg, Gropengießer, 2001; Liebers, 2004) and which easily could be implemented in a classroom. More sophisticated experiments such as wind tunnels and other lift exhibits are only available in out-of-school settings like science centres or research laboratories; they are not easy accessible for school classes, for instance, due to availability, distances, time-frames of the school curricula and/or money resources. Hence, teachers often may only resort to "traditional demonstration-experiments" when teaching bird flight in classrooms. However, this limitation contradicts the demand for teaching science by inquiry in learner-centred environments with hands-on experimentation (Bybee, 2000; Hofstein \& Lunetta, 2003; Hofstein \& Rosenfeld, 1996). In an attempt to facilitate a teaching approach of the curriculum-based subject of birds and bird flight, we developed an educational unit based mainly on workstations (Sturm \& Bogner, 2008; Sturm \& Bogner, 2010). The interactive model focuses on a selected aspect of bird flight and lift in general by focusing on the aerodynamic resistance of different formed bodies. 
All flying (and swimming) objects or animals commonly follow an aerodynamic feature. This precondition is needed to maximise propulsive forces (whether in air or in water) with a minimum of energy investment (Stöcker, 1994). Thus, aerodynamic aspects need appropriate consideration within teaching lessons about bird flight in Biology or the issue of lift in Physics. However, in the relevant literature we could not allocate any hands-on experiment dealing with aerodynamic features and allowing an appropriate and uncomplicated implementation in a school classroom setting. Therefore, we developed an interactive "track model" where students could investigate aerodynamic features of differently formed bodies in an hands-on approach. This present article describes the track model itself, its implementation and evaluation. Simultaneously, it monitors the cognitive understanding of aerodynamic aspects as well as the involved affectivity and handsomeness when dealing with the track model.

\section{Design and Methods}

\subsection{Construction of the "Track Model"}

The exhibit consists of: an aluminium profile $(1=164 \mathrm{~cm})$; few railway tracks $(1=124 \mathrm{~cm})$ including two track stoppers; a tape measure; two tripods; one hairdryer (front diameter $=5,5 \mathrm{~cm}$ ); a small piece of coloured, adhesive tape; four railway wagons; four differently shaped wooden bodies; flexible screw thread $(1 \sim 1,5 \mathrm{~m}$; diameter $=3 \mathrm{~mm})$ and $6-8$ appropriate nuts; small metal pieces.

\section{$<$ Figure 1 about here $>$}

Conventional railway tracks with track stoppers on both ends were screwed on a longitudinal aluminium profile. A conventional tape measure was fixed on one side, starting with zero on the right side. The aluminium bar with the railway tracks above was fixed between two tripods (with a distance (d) of the tripods of $139 \mathrm{~cm}$ from each other), showing a declination angle of $\alpha=0.5^{\circ}(\mathrm{h}=1,2 \mathrm{~cm} ; \mathrm{h} / \mathrm{d}=\tan \alpha$; Figure 1 and 2$)$. A hairdryer was located as shown in Figure 1 (at the lower end of the aluminium profile, where the tape measure starts with zero). The upper end of the railway track was marked with a yellow tape indicating the starting point of the wagon. Four different featured wooden bodies (Figure 1 shows three bodies, as A can be used differently with its both ends) were hooked to railway wagons: a hole of 3 millimetres was bored in each body and a flexible screw thread was turned in and curved. The other end of the screw thread was fixed with nuts in a railway wagon (only the basis of the wagon was used). It was taken specific care that all four screws did not differ in length, and the weight of the four objects (body + wagon $=135 \mathrm{~g}$ ) was equilibrated with metal pieces fixed on the wagons.

\subsection{Theoretical background of the "Track Model"}

A wagon on the declining track moves downwards to the positioned hairdryer. Acting forces can be split up in a downhill-slope force (Fh), a weight $(\mathrm{G})$ and a normal force $(\mathrm{Fn})$, whereas Fh equals $\mathrm{G} \sin \alpha(\alpha$ is the angle which encloses the inclined plane and the horizontal bases) (Figure 2).

\section{$<$ Figure 2 about here $>$}

The hairdryer's air stream simulating the oncoming air to a flying object or animal is supposed to be cone-shaped. Close to the hairdryer, the velocity (v) of the air stream is high; with increasing distance, the velocity of the air stream is decreasing. Starting at the yellow mark (upper point of the track, see Figure 1), a wagon and its fixed body moves down approaching the hairdryer. Firstly, the downhill-slope force Fh is increasing, but when approaching the hairdryer, the air velocity gets higher and amplifies the resistance force $(\mathrm{Fw})$. At a specific point, the forces $\mathrm{Fh}$ and $\mathrm{Fw}$ become equal: the wagon stops. The resistance force (or drag) is defined through the following equation (Gerthsen \& Vogel, 1993 [p. 112]):

$\mathrm{FW}=1 / 2 \mathrm{cW} \rho$ v2 A

$(\mathrm{FW}=$ resistance force $(\mathrm{drag}) ; \mathrm{cW}=$ drag coefficient; $\rho=$ density of the air; $v=$ velocity of the air stream; $\mathrm{A}=$ cross section surface).

All four different shaped objects have the same weight $(\mathrm{G})$ and thus an identical downhill-slope force Fh is acting on them. Also, the cross-section surface A is the same for all bodies. The drag coefficient $\mathrm{cw}$ is the varying parameter in our experiment. $\mathrm{Cw}$ depends on the feature of the front surface of an object. Table 1 details selected $\mathrm{cw}$-values for different features (Stöcker, 1994).

\section{$<$ Table 1 about here $>$}

Aerodynamic shaped objects have lower cw-values than non-aerodynamic features do. Assigned on the above described equation, lower $\mathrm{cw}$-values require a higher velocity to "fulfil" the equation given by a constant $\mathrm{Fw}$ (if $\mathrm{Fw}=\mathrm{Fh}$ ). The air velocity is increasing with a decreasing distance to the hairdryer. Thus, the closer an object approaches the hairdryer, the more aerodynamic is its feature, due to a lower cw-value. However, the objective of our hands-on experimenting with 
the track model is not to measure specific cw-values of different items and not to calculate any physical equations, but it is to record the distance of the bodies to the hairdryer when $\mathrm{Fw}=\mathrm{Fh}$. Thereby, a specific learning goal points to an understanding that aerodynamic features contribute more properly towards an economic flying situation than non-aerodynamic features do.

\subsection{Content of student's experiments with the "Track Model"}

Students were guided through the experiment by a worksheet included in the workbook for the individual workstations. Firstly, they had to hypothesise (task-1) and secondly, to reason (task-2) which one of the bodies on the table they assume to be the best for constructing an flying object. Thirdly, they had to test which of the flying objects (the bodies) would be best: The instruction was to put one wagon on the track at the side with the yellow mark. Before releasing the wagon, another student had to switch on the hairdryer. When the wagon has stopped, the students had to read off the appropriate value on the measure tape and record it in the worksheet. All four different-shaped objects had to be tested analogous (task-3). The next task consisted of a group discussion of the results to list potential explanations for the different values in the workbook (task-4). Lastly, the students had to suggest a definition for an "aerodynamic form" (task-5). Thus, scientific learning challenge included to raise hypotheses and to reason them appropriately (task-1 and 2); to do hands-on experiments properly (task-3) as well as to discuss experimental results within the group (task-4 and 5).

\section{Implementation and Evaluation of the "Track Model"}

The track model was one of eight workstations dealing with the subject of birds and bird flight (Sturm \& Bogner, 2008). Altogether, 262 A-level 6th graders of eleven school classes participated in our study (average age was 12.5). Working together in groups of three to five students, each school class had about 90 minutes available in order to complete all eight workstations. The evaluation of the specific track model station comprised a semantic differential and qualitative analyses of a sub-sample of workbooks. A semantic differential (Osgood et al, 1957) which was implemented immediately after completing all workstations monitored the affectivity and usability of our exhibit from a students' point of view. The test itself consisted of eight opposing word pairs (important/not important; definite/not definite; interesting/not interesting; easy/difficult; easy to understand/difficult to understand; motivating/not motivating; essential/unimportant; useful/not useful) and was answered in a 5-score scale by considering the initial statement: "Experimenting with the track model was ..." The students' responses were recoded to "1" for the most negative nomination and to "5" for the most positive nomination. Statistic analyses were conducted with SPSS 14.0. Reliability analysis of the semantic differential showed a Cronbach's $\alpha$ of 0.82 .

Additionally, the workbooks of 60 students (specifically the section for the track model) were analysed in order to test the usability and effectiveness of students' understanding of aerodynamic aspects. We only analysed a sub-sample of all participants since group-members often gave identical answers to questions in the workbook; hence, we singled out randomly one workbook per group. In task-1, one score was given when students named object "B" as the most suitable one, none for other assumptions. In task-3, the measured and recorded scores of the students' experiments varied throughout the trials, just because the angle of alpha was not identical in all assessment trials. This discrepancy reasons in different-sized classroom tables where the tripods could not be fixed exactly in a distance of $139 \mathrm{~cm}$. Therefore, task-3 was valuated with one score when students recorded numbers in an ascending order of the objects: "B" and "A2" are the most aerodynamic objects and thus show lower numbers than "A1" and "C". The procedure of analysing task-2, 4 and 5 was first to find categories of answers for each task. All categories have then been predefined in "incorrect" or "correct" and encoded by letters. Subsequently, all 60 answers were classified by assigning the appropriate category code and were finally summarized (Mayring, 2003 [p. 74-76]). Objectivity of the assignment to the categories was tested by determining Cohen's kappa (Zöfel, 2002 [p. 167-169]); its score indicates the degree of congruence of nominal scaled data of two independent persons (Cohen, 1968 [p. 214]). For both persons, Cohen's kappa was 0.82. Kappa-coefficients above 0.7 indicate adequate objectivity and signals sufficient reliability (Lienert \& Raatz, 1998 [p. 140]).

\section{Results}

A Principal Component Analyses (PCA) with varimax rotation based on all semantic differential responses extracted two factors with eigenvalues of 3.65 and 1.36 explaining $63 \%$ of variance. Factor-1 comprised five items (important [factor loading $=.73]$; interesting $[\mathrm{fl}=.71]$; motivating, $[\mathrm{fl}=.69]$; essential $[\mathrm{fl}=.74]$; useful $[\mathrm{fl}=.78]$ ) and factor-2 included three items (definite $[\mathrm{fl}=.73]$; easy $[\mathrm{fl}=.82]$; easy to understand $[\mathrm{fl}=.89]$ ). Figure 3 shows the specific mean scores of both factors labelled "efficacy" and "easiness". Obviously, students valued the track model very high, as "5" is the most positive rating on the scale.

$<$ Figure 3 about here $>$

Qualitative analyses of the workbooks revealed for task-1 that 45 out of 60 students quoted body "B" as best replica 
for constructing a flying object. Hence, $75 \%$ of the students indicated a correct assumption before conducting the experiment. They reasoned their assumption (task-2) with a "streamlined shape" $(\mathrm{n}=11)$, or with "windschnittig" ( $=7)$, "aerodynamic" $(\mathrm{n}=4)$, "low aerodynamic resistance" $(\mathrm{n}=11)$, or with "similarities with birds or aeroplanes" $(\mathrm{n}=8)$. These answer categories were predefined as correct answers. Inadequate or incorrect answers belonged to the categories "propulsion because of the hole" $(n=11)$, "narrow / small / cone-shaped" $(n=4)$, and four answers could not assigned at all to any category. Thus, $68 \%$ of the students gave correct answers in task- 2 , whereof $65 \%$ of the students gave correct answers in both, tasks-1 and -2. Obviously, students already followed a certain concept of "aerodynamic" before conducting any experiment. Task-3 was the hands-on part of the "track model" workstation. A typical series of measurements: $\mathrm{A} 1=63 \mathrm{~cm} ; \mathrm{A} 2=27 \mathrm{~cm} ; \mathrm{B}=0 \mathrm{~cm} ; \mathrm{C}=52 \mathrm{~cm}$ was considered as correct sequences which was measured by $85 \%$ of the students. Nine students recorded an incorrect sequence, eg, $\mathrm{A} 1=0 \mathrm{~cm} ; \mathrm{A} 2=94 \mathrm{~cm} ; \mathrm{B}=15 \mathrm{~cm} ; \mathrm{C}=122 \mathrm{~cm}$. In task-4, students had to discuss their results. 56 students explained their results correctly. For example, one student said "A1 is retarded because of the concavity of the front side; A2 is streamlined, allowing the air passing sidewise; B is also streamlined; in C, aerodynamic resistance is huge due to its corners". In the following task-5, 46 students were able to give a correct definition of "aerodynamic", six students could not be assigned to any category and eight students wrote down an explanation which was not incorrect, but considered to be incomplete (Table 2).

$<$ Table 2 about here $>$

To sum up, 28 of 60 students (47\%) have correctly answered all five tasks of the track model workstation. Task-3, 4 and 5 was correctly answered by 40 students (67\%) leaving 12 students $(20 \%)$ with incorrect assumptions or explanations before conducting the experiment; nevertheless, the latter explained their results correctly and gave a definition of "aerodynamic" after the experiment. Hence, $20 \%$ of the students reached a new understanding by doing the experiment with the track model.

\section{Discussion and Conclusions}

In analysing the affectivity of the model and its ability to demonstrate aerodynamic aspects we found in a semantic differential a clear splitting and assignment of all eight items into two factors with high consistent loadings. Furthermore, the students valued both factors very high, above the average mean of the scale. One factor ("easiness") consisted of the items "definite", "easy" and "easy to understand"; obviously, the students perceived the track model as easy, appropriate and clear to follow. The factor "efficacy" comprised, for example, "interesting" and "motivating", which are self-explanatory. Thus, our results may indicate a high affective component when using the track model. Although no control group - in a conventional sense - was included, we may rely on these results because of a high reliability coefficient of the semantic differential scale (Lienert \& Raatz, 1998).

Workbook analyses of the students' experiments with the track model revealed that $67 \%$ of the students carried out the experiment and answered the subsequent questions in a correct way; and $20 \%$ of them definitely learnt by conducting the experiments. These students indicated wrong assumption before conducting the experiment, but by experimenting with the track model, subsequent questions (task-4 and 5) were answered correctly. These results are very convincing. However, we presume that the percentage might even be increased by including a final wrapping-up discussion with the teacher. Some students misunderstood the track model in a way that just those objects are doing best which came to a halt at a larger distance to the hairdryer. A short recapitulation and dialogue with the teacher might clarify and avoid those misunderstandings. Nevertheless, the results indicate the self-explanatory value of using our track model.

Some difficulties came up with the analyses of task-3 with regard to the huge variance within the recorded scores of the experiment. As reasoned above, the variance is due to logistic reasons. However, it is not necessary that all students measure exactly the same values, but that students drawing correct conclusions of their experiments. Therefore, the evaluation of task-3 is more a matter of the experiment's quality rather than the students' ability to measure or conduct the specific experiment. Hence, if the track model would be standardized, more students are expected to come up with identical values at all. Furthermore, the different sizes of the bodies could mislead students in the discussion of their results. Although the weight of the bodies was equalized with metal pieces, some students reasoned their results with the different sizes of the bodies. Following implementations of the track model should use bodies of equalized weight and sizes.

Even if the track model itself could be improved, we assume a great potential of its implementation in school. The model could be used in Biology and Physic lessons. It also might suit higher grade Physic students to determine cw- or Fw-values. Constructing the model requires a small amount of time and just low money efforts which are ideal prerequisites of class projects. The model is easy to implement and demonstrative. Learning by inquiry is realized as well as students practice group-working: although the experiments could be done by one student, it is much easier and more favourable to accomplish the experiments in a team. Hence, students learn basic issues of scientific research and 
working (Finn et al, 2002). Overall, hands-on and experimentation could increase motivation and interest in a subject (Sturm \& Bogner, 2008), and thus, add to the individual learning process (Black \& Deci, 2000). Nundy (2001) claims a mix of teaching and learning approaches, including hands-on and differentiated learning, to meet the needs of the whole class. Like school excursions, self-conducted experiments are a break in the school routine (Kisiel, 2003). The less formal atmosphere of laboratory activities (they define science laboratory activities as learning experiences in which students interact with materials and/or with models to observe and understand the natural world) could enhance constructive social relationships, positive attitudes and cognitive growth (Hofstein \& Lunetta, 1982; Lazarowitz \& Tamir, 1994). Based on our study, we conclude that any working with the track model may simultaneously address affective and cognitive components as well. In our view, it is worthwhile to integrate the track model in science curriculum and therefore invite educators to rebuild and apply the model.

\section{References}

Anderson, D. F. \& Eberhardt, S. (2001). Understanding Flight. New York: McGraw-Hill.

Black, A. \& Deci, E. (2000). The effects of instructors' autonomy support and students' autonomous motivation on learning organic chemistry. A self-determination theory perspective. Science Education. 84, 740-756. http://dx.doi.org/10.1002/1098-237X(200011)84:6<740::AID-SCE4>3.0.CO;2-3

Bybee, R. W. (2000). Teaching science by inquiry. Inquiring into inquiry learning and teaching in science. 20-46.

Cohen, J. (1968). Weighted Kappa: Nominal Scale Agreement with Provision for Scaled Disagreement or Partial Credit. Psychological Bulletin. 70, 213-220. http://dx.doi.org/10.1037/h0026256

Finn, H., Maxwell, M. \& Calver, M. (2002). Why does experimentation matter in teaching ecology? Journal of Biological Education 36(4) 158-162. http://dx.doi.org/10.1080/00219266.2002.9655826

Gerthsen, C. \& Vogel, H. (1993). Physik (17 ed.). Berlin: Springer-Verlag.

Gropengießer, I. (2001). Vom Fliegen. Unterricht Biologie. 267.

Hofstein, A. \& Lunetta, VN. (2003). The Laboratory in Science Education: Foundations for the Twenty-First Century.

Hofstein, A. \& Lunetta, VN. (1982). The role of the laboratory in science teaching: Neglected aspects of research. Review of Educational Research. 52(2) 201-217.

Hofstein, A. \& Rosenfeld, S. (1996). Bridging the Gap between Formal and Informal Science Learning. Studies in Science Education. 28, 87-112. http://dx.doi.org/10.1080/03057269608560085

Kisiel, J. F. (2003). Teachers, museums and worksheets: A closer look at a learning experience. Journal of Science Teacher Education. 14(1) 3-21. http://dx.doi.org/10.1023/A:1022991222494

Lazarowitz, R. \& Tamir, P. (1994). Research on Using Laboratory Instruction in Science. In D. L. Gabel (Ed.), Handbook of Research on Science Teaching and Learning (pp. 94-128). New York: Macmillan Publishing Company.

Liebers, K. (2004). Vom Fliegen. Berlin: Cornelsen.

Lienert, G. A. \& Raatz, U. (1998). Testaufbau und Testanalyse. Weinheim: Psychologie Verlags Union.

Mayring, P. (2003). Qualitative Inhaltsanalyse (8 ed.). Weinheim: Beltz-Verlag.

Nundy, S. (2001). Raising achievement through the environment: a case for fieldwork and field centres. In National Association of Field Studies Officers. Peterborough.

Osgood, C. F., Suci, G.J. \& Tenenbaum, P.H. (1957). The measurement of meaning. Urbana: Illinois: University of Illinois Press.

Stöcker, H. (1994). Taschenbuch der Physik (2 ed.). Frankfurt am Main: Verlag Harri Deutsch.

Sturm, H. \& Bogner, F.X. (2008). Student-oriented versus teacher-centred: The effect of learning at workstations about birds and bird flight on cognitive achievement and motivation. International Journal of Science Education. 30(7) 941-959. http://dx.doi.org/10.1080/09500690701313995

Sturm, H. \& Bogner, F.X. (2010). Learning at workstations in two different environments: A museum and a classroom. Studies in Educational Evaluation. http://dx.doi.org/10.1016/j.stueduc.2010.09.002

Zöfel, P. (2002). Statistik verstehen. Ein Begleitbuch zur computergestützten Anwendung. München: Addison-Wesley Verlag. 
Table 1. Drag coefficients $\left(\mathrm{c}_{\mathrm{w}}\right)$ for different featured surfaces (Stöcker, 1994); arrows indicate incoming air; four different shaped features are used in the track experiment.

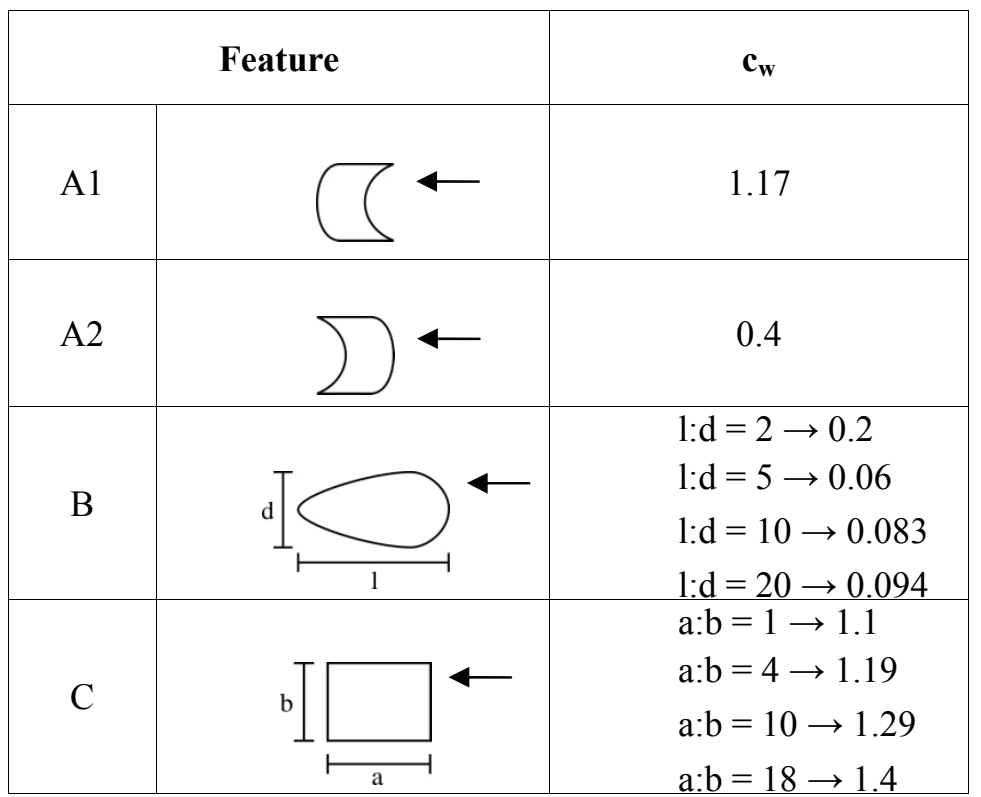

Table 2. Correct answers of the track models' tasks

\begin{tabular}{|c|c|c|}
\hline $\mathbf{N}=\mathbf{6 0}$ & \multicolumn{2}{|c|}{$\begin{array}{c}\text { Students with correct } \\
\text { answers }\end{array}$} \\
\hline & $\mathbf{n}$ & $\mathbf{\%}$ \\
\hline Task-1 & 45 & 75 \\
\hline Task-2 & 41 & 68 \\
\hline Task-3 & 51 & 85 \\
\hline Task-4 & 56 & 93 \\
\hline Task-5 & 46 & 77 \\
\hline
\end{tabular}

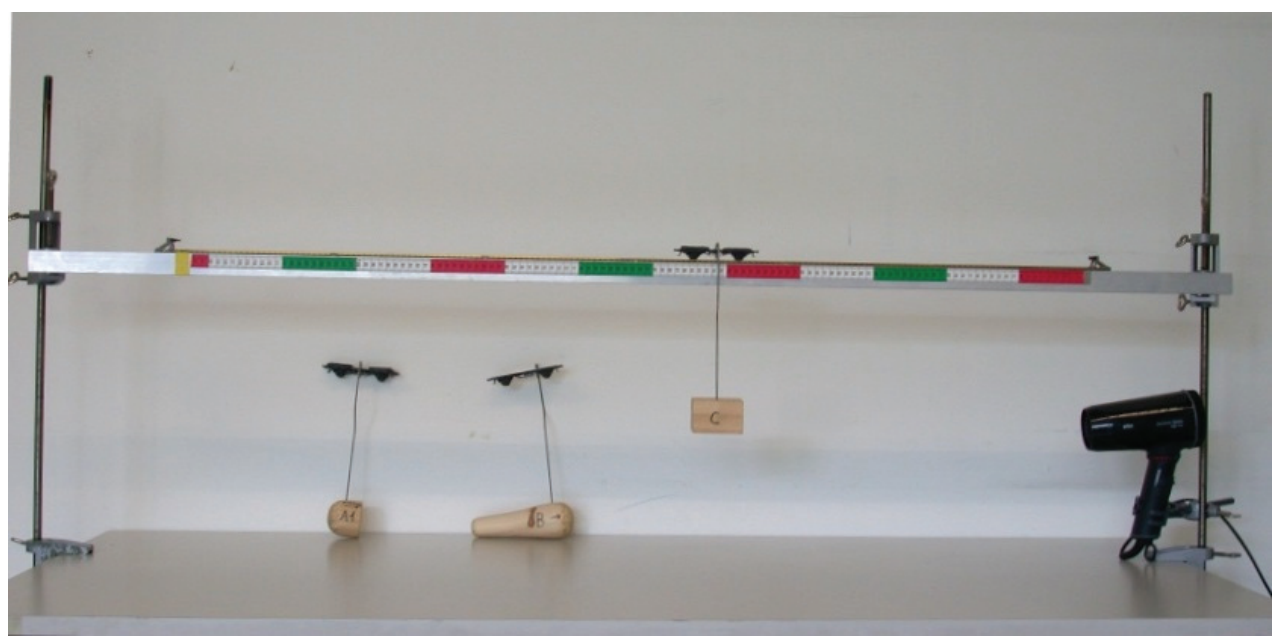

Figure 1. Track model and differently shaped objects.

Object A is concaved at one side (A1) and convexed on the other end (A2) which allows an double-usage for two directions 


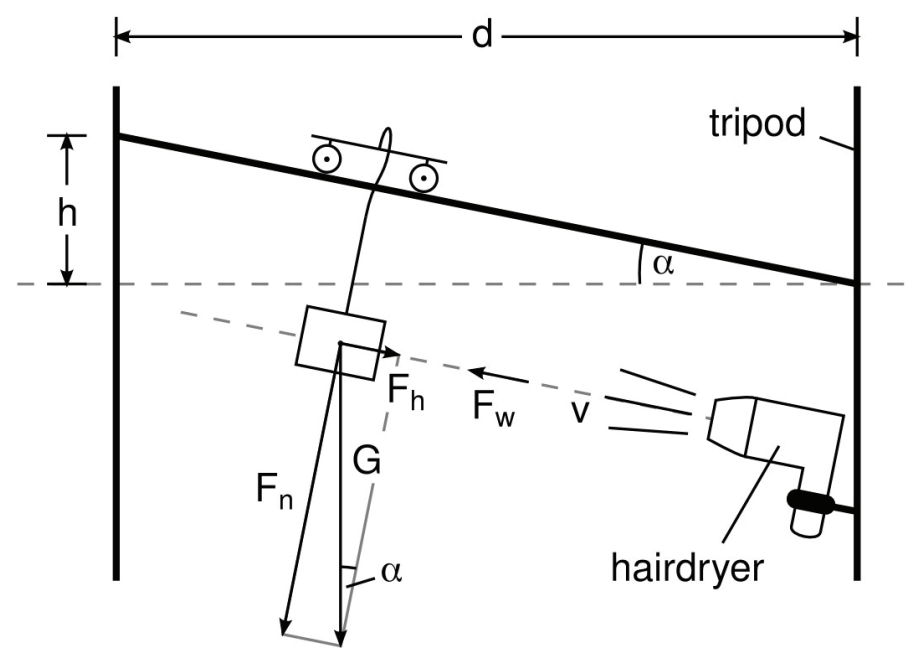

Figure 2. Schemata of the acting forces when an object moves down and approaches the hairdryer.

The declination angle $\alpha$ is defined by: $\mathrm{h} / \mathrm{d}=\tan \alpha\left(\alpha=\right.$ declination angle, $\mathrm{F}_{\mathrm{n}}=$ normal force, $\mathrm{F}_{\mathrm{h}}=$ downhill-slope force $F_{w}=$ resistance force, $G=$ weight of the object, $v=$ velocity of the air stream)

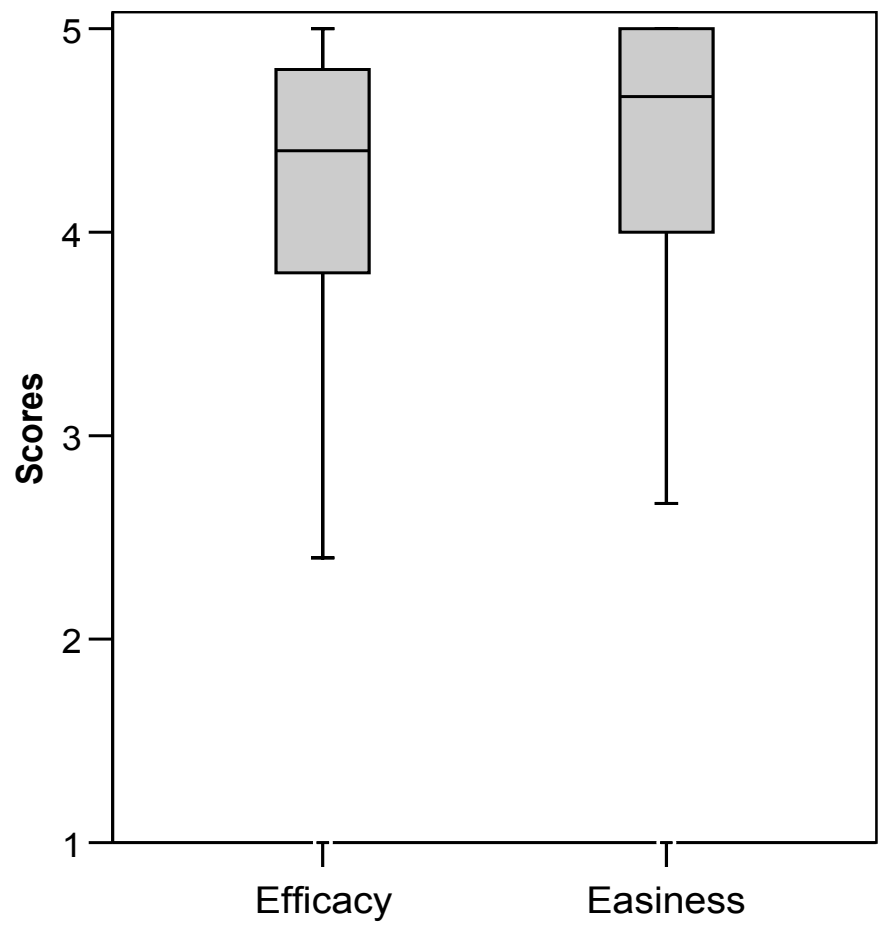

Figure 3. A factor analysis of the semantic differential extracted two factors: "efficacy" (5 items) and "easiness" (3 items) (*"5" means the most positive rating) 